\title{
Analysis of the effect of COVID-19 on air pollution: perspective of the Spanish case
}

\author{
Javier Cárcel-Carrasco ${ }^{1}$ [D • Manuel Pascual-Guillamón ${ }^{1} \cdot$ Jaime Langa-Sanchis ${ }^{1}$
}

Received: 5 October 2020 / Accepted: 1 March 2021 / Published online: 12 March 2021

(C) The Author(s), under exclusive licence to Springer-Verlag GmbH Germany, part of Springer Nature 2021

\begin{abstract}
The pandemic caused by coronavirus COVID-19 is having a worldwide impact that affects health and the economy and indirectly affects air pollution in cities. In Spain, the effect has evolved from being anecdotal in January 2020 to become the second country in Europe with the highest number of cases (614,000 cases by 17/09/2020), which has affected the health system and caused major mobility restrictions. In contrast, COVID-19 has affected air pollution and energy consumption in the country. This article analyzes the indirect effect produced by this pandemic on air pollution, referenced to various stages that occurred in Spain: first stage, without public awareness of COVID-19 impact (mid-January 2020); second is when Spanish Government alerted (late February 2020); and third, after the decree of alarm and mobility restriction of citizens by the government (March 2020) along with the various phases of the de-escalation. The indirect effect produced by this pandemic on air pollution in Spanish cities has been resulted in a decrement of $70 \%$ to $80 \%$ of average, taking into account dates after the decree of alarm and mobility restriction by the Spanish government (14/03/2020), compared to days prior to that date. Thus, the results of this analysis indicate a significant alteration in air pollutants; these alteration patterns have followed similar paths over different countries worldwide improving the air quality as discussed by Dutheil et al. (Environ Pollut (Barking, Essex: 1987) 263:114466, 2020).
\end{abstract}

Keywords Air pollution $\cdot$ COVID-19 $\cdot$ Air quality $\cdot$ Cities $\cdot$ Energy

\section{Introduction}

The COVID-19 outbreak has impacted worldwide which led to the stoppage of economic activities and the drop of stock markets. In order to prevent the transmission of the virus also known as SARS-CoV-2 (COVID 19), precautionary measures have been taken such as masks and gloves on daily basis along with mobility restrictions in case of the increasing tendency of the COVID-19 infections. Undoubtedly, the negative effect of coronavirus is led by more than 926,544 deceased

Responsible Editor: Gerhard Lammel

Javier Cárcel-Carrasco

fracarc1@csa.upv.es

Manuel Pascual-Guillamón

mpascual@mcm.upv.es

Jaime Langa-Sanchis

jailansa@csa.upv.es

1 Universitat Politècnica de València, Camino de Vera s/n, 46022 València, Spain people (WHO 2020a, b), and 29 million cases worldwide detected on 17th September of 2020, and the number continues to grow in countries such as India, Brazil, and the USA. The distribution of the affected countries is shown in Fig. 1, which originated in China, and the affected countries detected on September 17th, 2020 (Web1 2020).

On the other hand, various environmental aspects have been influenced by the pandemic. Factors such as a drastic closing of economic activity, industry, and transport have affected the environment indirectly reducing the number of air pollutants such as $\mathrm{PM}_{10}$ and $\mathrm{NO}_{2}$. Satellite images show the reduction of $\mathrm{CO}_{2}$ up to $25 \%$ in China due to the coronavirus crisis (approximately 200 million tons) (EPA 2020). After the pandemic impact on Italy, satellite images were taken by the European Space Agency (ESA) also show the decrease of pollutant concentration, such as nitrogen dioxide $\mathrm{CO}_{2}$ (ESA 2020) (a toxic compound that negatively affects the air quality, in addition to being a greenhouse gas) in the country. A reduction of air pollutants is common during times of crisis (Web2 2020). This is due to less mobility of people and transportation among with the reduction of economic activities that depend on fossil fuel, responsible for $\mathrm{CO}_{2}$ emission. This gas 


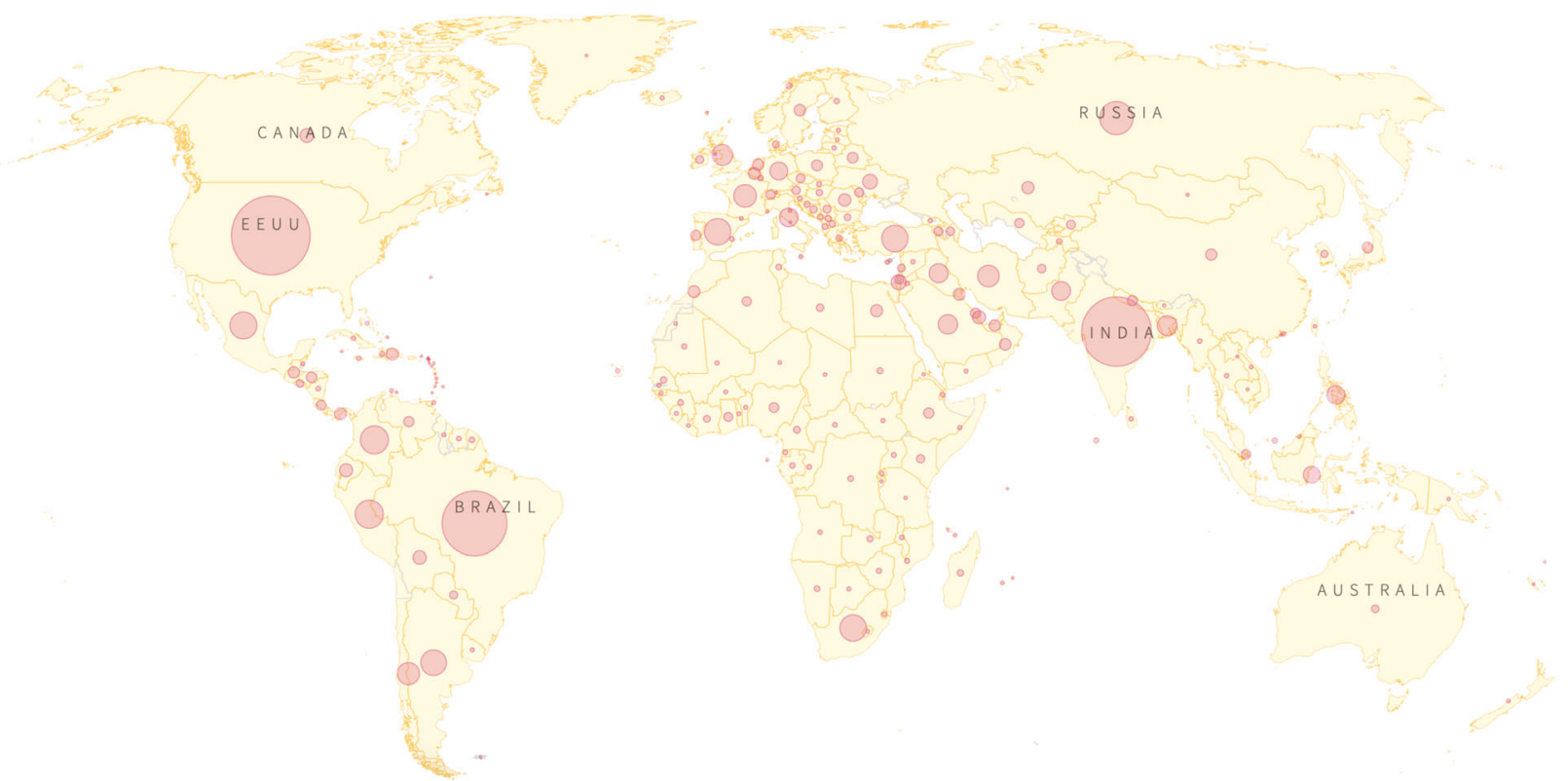

Fig. 1 Countries with reported confirmed cases of COVID-19, September 17th, 2020. Source: Reuters

is one of the main greenhouse gases, while $\mathrm{NO}_{2}$ is a highly toxic gas associated with vehicles that run on diesel. Although initially, these measures have created positive impacts on the environment, researchers fear that the situation will turn back once the pandemic is overcome. The International Energy Agency (IEA) can pose a threat to climate action in the long term, by reducing the investment in clean energy (IEA 2020). It should be taken into account that with the revitalization of the economy, pollution levels will rise again. However, this situation can be controlled by taking necessary measures to reduce greenhouse gas emissions. On the other hand, it is worth mentioning the tendency of air quality within international cities analyzed over a similar period of time as it is in this paper. Regarding the Asian continent, the values of air pollutants are presented at higher rates as the most polluted cities are located in this continent (Rodríguez-Urrego and Rodríguez-Urrego 2020). Despite having a higher pollution rate, it is noticeable the decreasing in air pollutants and their emissions once the outbreak of COVID-19 started (Rojas et al. 2021) and how it has been linked to the disease since the outbreak.

The current situation of COVID-19 cases is shown in Fig. 1 (Web1).

In the case of Spain, the COVID-19 infections increased exponentially due to the lack of awareness by the Spanish citizens which led to a total amount of $1,160,083$ cases reported on the 29th of October 2020. It is remarkable the other causes of deceases in Spain; 10,000 annual deaths are caused by air pollution, a number much higher than the mortality associated with traffic accidents, which is 1700 deaths per year, according to the Spanish Society of Pneumology and Thoracic Surgery (SEPAR 2020). Moreover, among the causes of death, tobacco is the third cause of death in the world, while air pollution is the fourth, with 7 million deaths worldwide, according to the World Health Organization (WHO 2020a, b). The most harmful environmental pollutants are nitrogen oxide $\left(\mathrm{NO}_{2}\right)$, which causes the most deaths in Spain (around 6000 a year), followed by suspended particles (2600 annual deaths) and tropospheric ozone (more than 500), and others like sulfur dioxide, carbon monoxide, or lead (WHO 2020a, b).

The global cost of fossil fuel has been quantified by different studies, showing an estimated cost of 8000 million dollars every day, around $3.3 \%$ of world GDP or 1.5 times the GDP of Spain (Farrow et al. 2020).

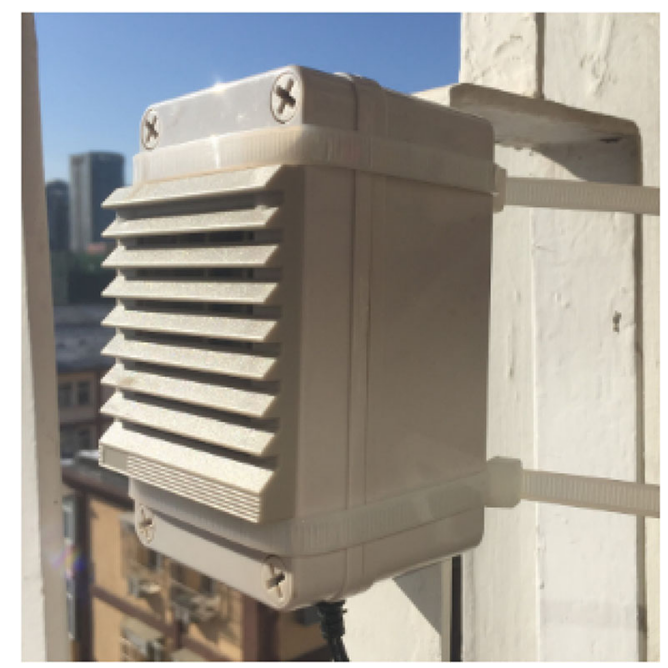

Fig. 2 Weather station GAIA A13 Monitoring Station 


\section{PM10 2019}

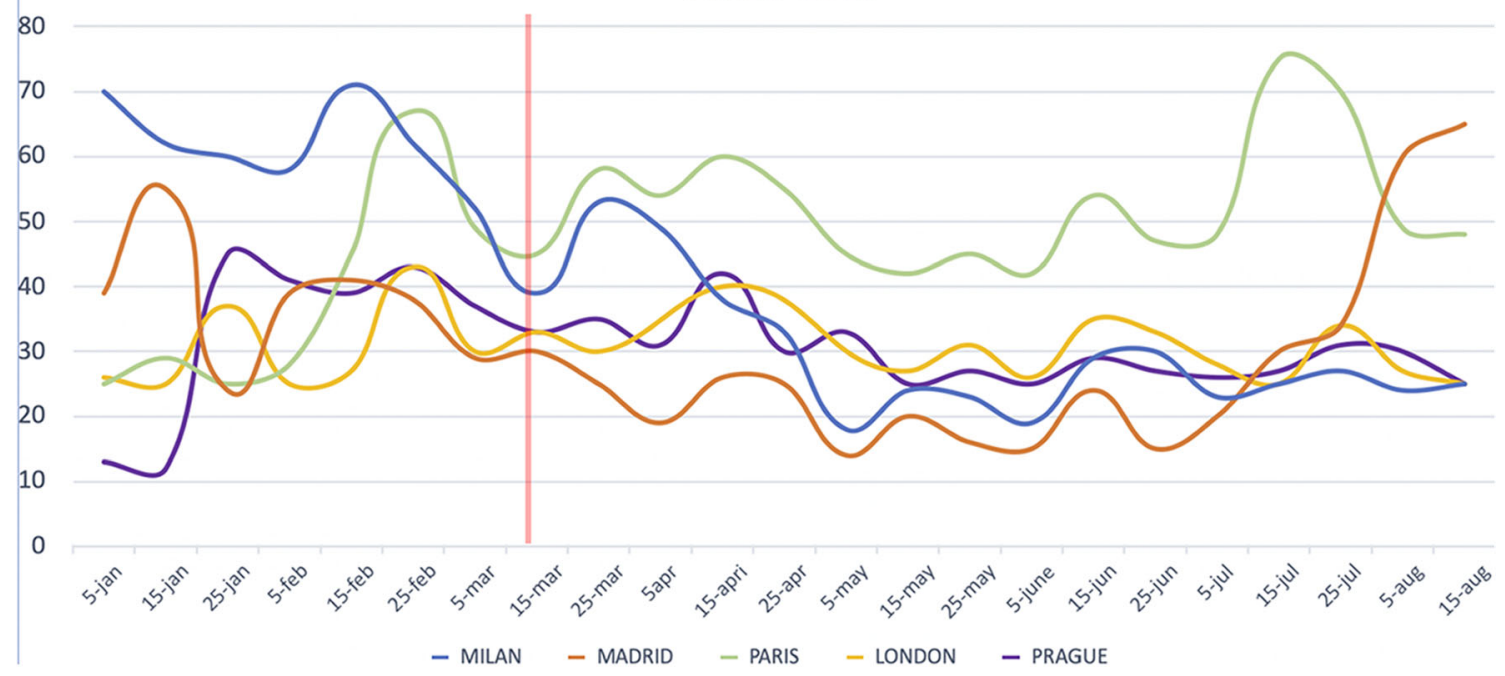

PM10 2020

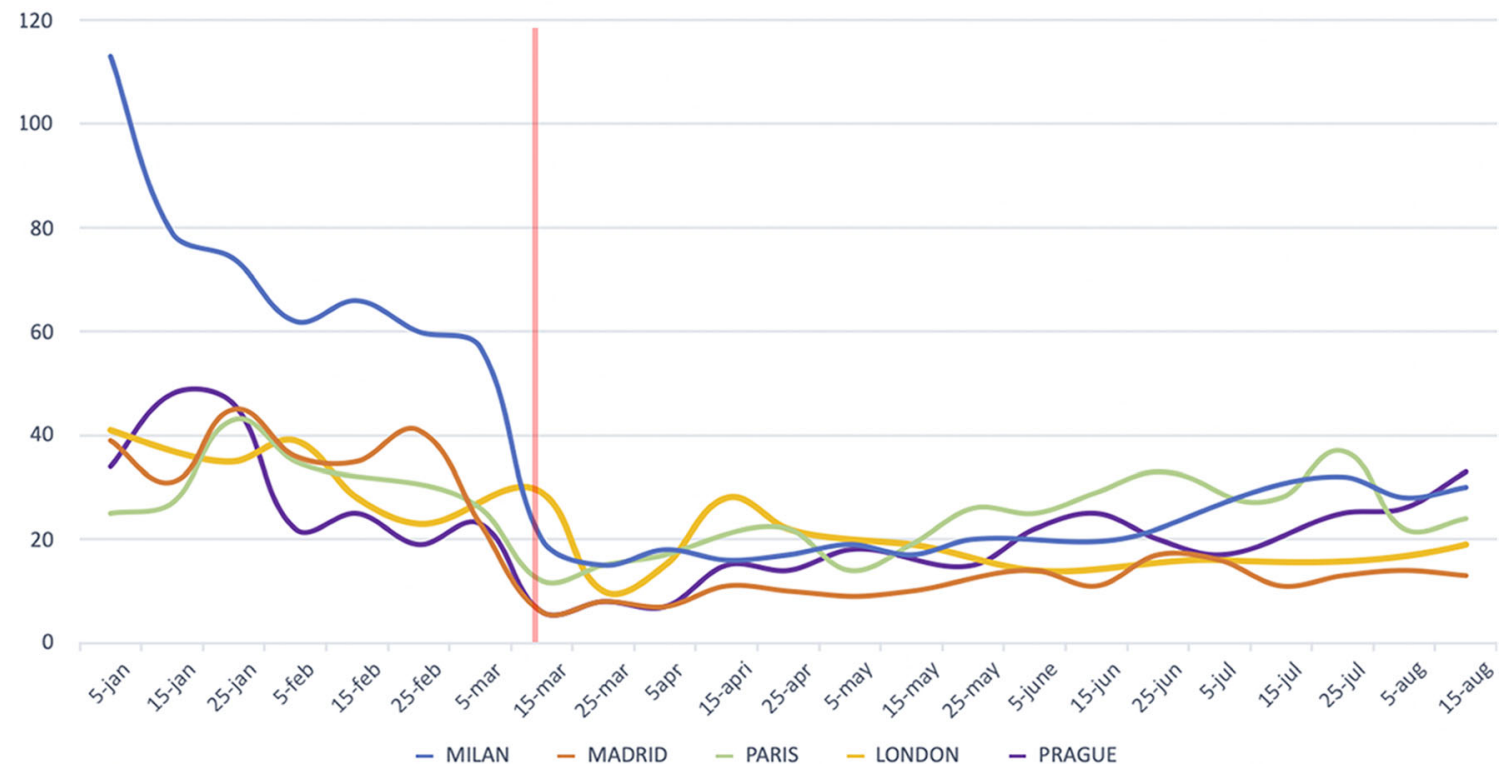

Fig. 3 Evolution of $\mathrm{PM}_{10}$ from January to August of 2020 and its comparison with 2019

Therefore, this article tackles the indirect effect produced by this pandemic on air pollution in reference to various stages that occurred in Spain. Five cities have been chosen in order to analyze the evolution of air pollution, cities such as Valencia, Madrid, Barcelona, Sevilla, and Bilbao. These cities are of high interest due to their large urban and high-traffic areas, where the rolled traffic on a daily basis is higher than other Spanish cities. The study for these cities has been conducted first, when there was no public awareness of the COVID-19 impact (mid-January 2020); second, when Spanish Government alerted (late February 2020); and third, after the decree of alarm and mobility restriction of the citizens by the government (March 14th, 2020), along with the different phases of the de-escalation. The state of alarm decreed by the Spanish government from March 14th imposes the confinement of citizens; the reduction of the circulation of private vehicles; reduction of busses, taxis, and railways services; and partial closure of Spanish airspace. These restrictions occurred at the same time in all Spanish cities.

\section{Materials and methods}

In order to analyze the effects of the pandemic caused by the COVID-19 virus on air pollution in Spain, the following resources and sources have been taken into consideration: 

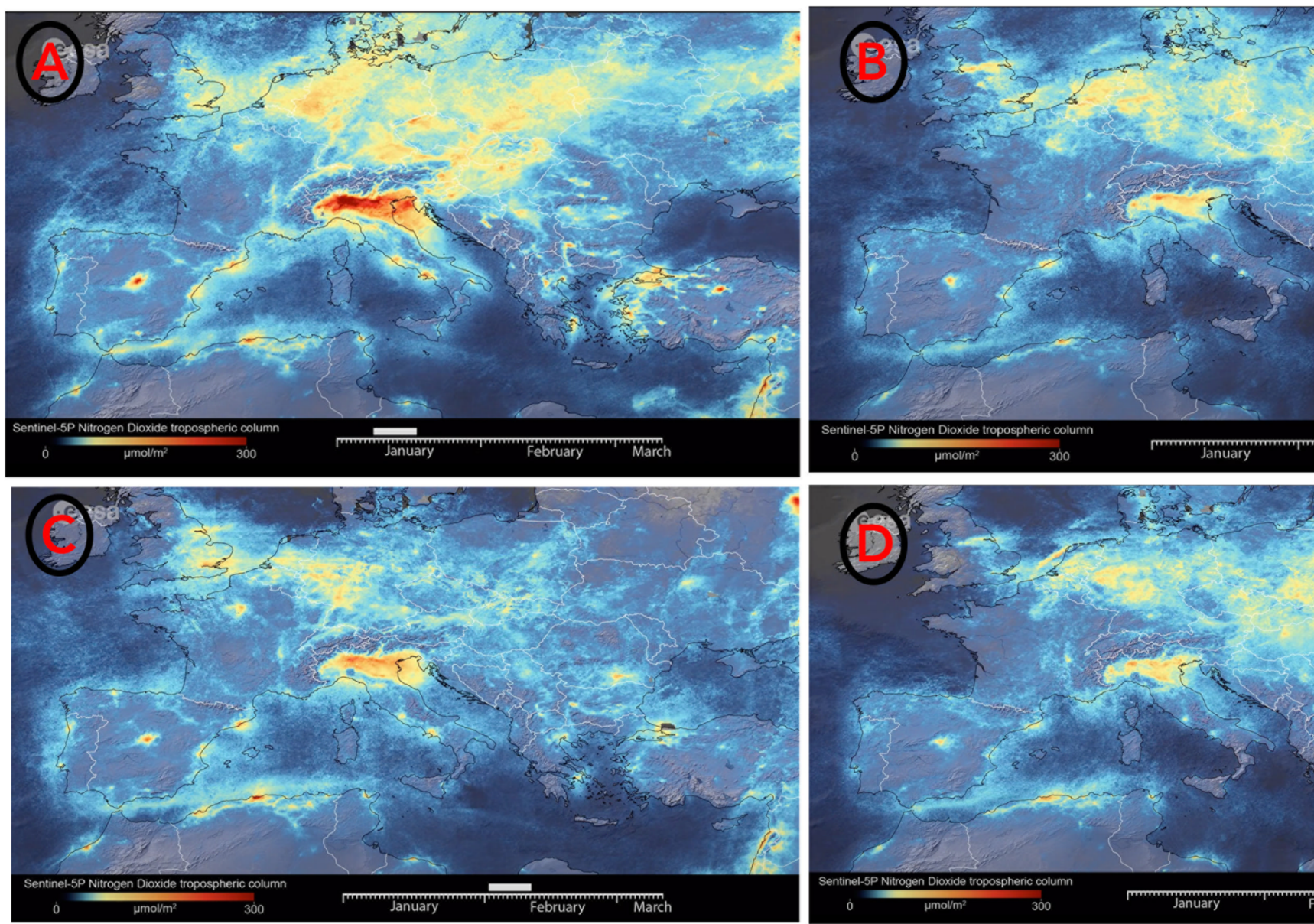

Fig. 4 Satellite views of nitrogen dioxide emissions $\left(\mathrm{NO}_{2}\right.$, redder on the map at high concentration). Top image (a, early January), bottom image (d, midMarch) (ESA 2020)

- The European Space Agency (ESA) and NASA pollution monitoring satellites (ESA 2020; NASA 2020). These satellites allow visualizing some side effects of the pandemic associated with air pollution of different regions. Sentinel-
$5 \mathrm{P}$ is the first Copernicus mission satellite devoted to monitoring our atmosphere. It has a Tropomi instrument that is capable of mapping numerous trace gases, such as nitrogen dioxide, ozone, formaldehyde, sulfur dioxide,
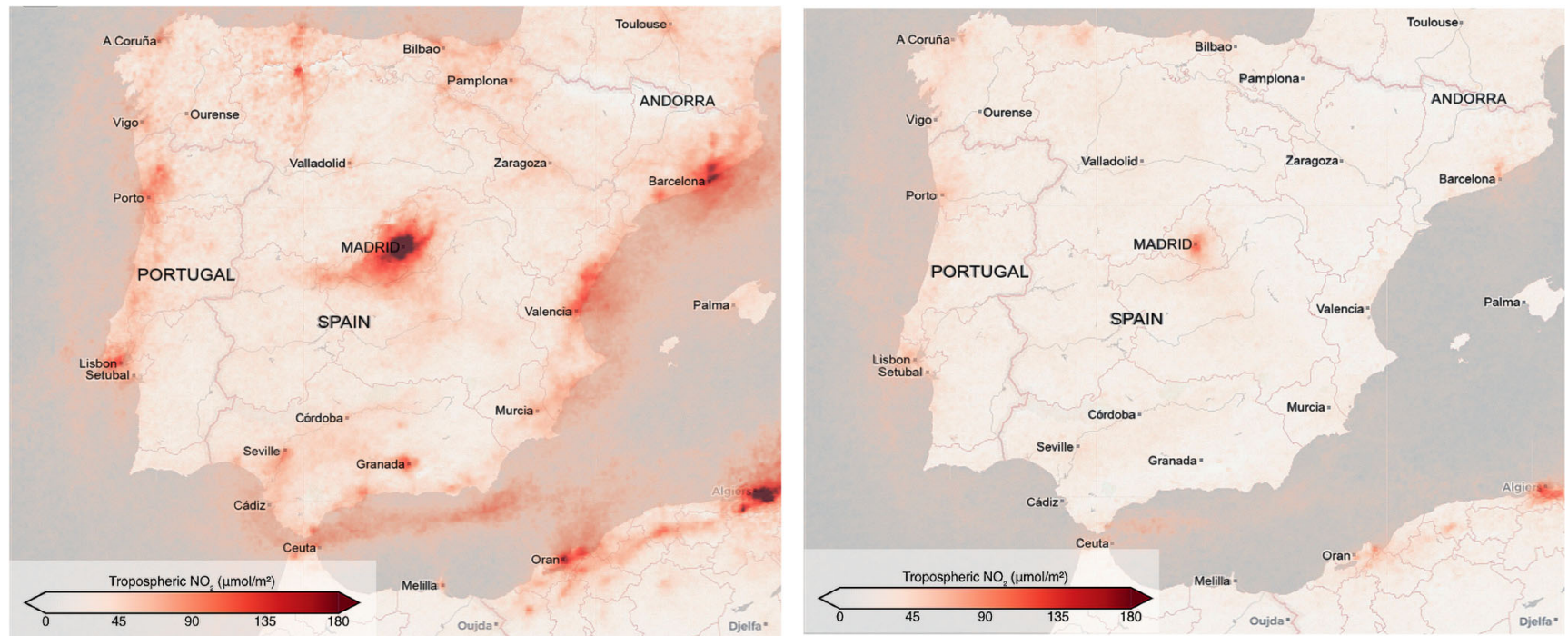

Fig. 5 Significant decreases in nitrogen dioxide $\left(\mathrm{NO}_{2}\right)$ over Spain. January 6th-April 13th, 2020 
methane, carbon monoxide, and aerosols, which affect the breathable air and, therefore, our health and environment. These satellite images will provide information on atmospheric quality, stratospheric ozone, and solar radiation, in addition to monitoring the weather.

- Atmospheric pollutants measurement station of Barcelona, Madrid, Valencia, Sevilla, and Bilbao in Spain along with European stations.

- Atmospheric pollutants measurement stations measure the main pollutant sources present in urban environments such as sulfur $\left(\mathrm{SO}_{2}\right)$ and nitrogen oxides (NO, $\left.\mathrm{NO}_{2}, \mathrm{NOx}\right)$, carbon monoxide $(\mathrm{CO})$, ozone $\left(\mathrm{O}_{3}\right)$, and the suspended particles with fractions less than $10 \mu \mathrm{m}$ $\left(\mathrm{PM}_{10}\right)$ and less than $2.5 \mu \mathrm{m}\left(\mathrm{PM}_{2,5}\right)$, and organic compounds (VOCs, benzene, toluene, xylene). Nitrogen oxides $\left(\mathrm{NO}_{2}\right)$ and $\mathrm{PM}_{10}$ require special attention. The first of them is originated by the combination of nitrogen and oxygen present in the air as a consequence of combustion processes, including road traffic, while $\mathrm{PM}_{10}$ particles are also originated during combustion processes (carbonaceous particles, soot), although they can also have a natural origin (fine sand and other particles) due to the wind. In addition to particle analysis, measurements of meteorological parameters are made to determine the dispersion of pollutants such as temperature, humidity, wind direction, and speed, as well as atmospheric pressure and solar radiation. The normally used model for the weather station is the model called GAIA-A13 (Fig. 2).

The Gaia A13 comes with 2 redundant PM sensors (so 3 in total). This setup is mandatory for "official" AQI readings (e.g., data broadcasted to a wide audience), as a way to ensure the data reliability of the PM sensors. The meteorological sensor is a high precision sensor for Relative Humidity, Temperature, and Pressure sensing.

- Particulate Matter Sensors: 3x PMS 5003

- Meteorological Sensors: BME 280

- Power Supply: 5 V (USB compatible)

- Connectivity: WIFI (with external antenna)

- Dimensions: $130 * 80 * 70 \mathrm{~mm}$

- Weight: $380 \mathrm{~g}$

\section{Analysis of the effect of COVID-19 on air pollution: perspective of Europe, Spain, and Italy}

European Space Agency (ESA) and NASA have detected significant decreases in nitrogen dioxide $\left(\mathrm{NO}_{2}\right)$ in Europe through pollution monitoring satellites. There is evidence that the change is related to the economic slowdown as a consequence of the coronavirus outbreak (ESA 2020). It is remarkable how in Europe the effect of air pollutants decreases in large urban areas as a consequence of mobility restriction and the stoppage of economical activity. First, in Italy and then in the rest of the major regions in Europe as it is observed in Fig. 3 showing the drop of $\mathrm{PM}_{10}$ in cities such as Milan, Madrid, Paris, London, and Prague. Figure elaborated with data collected from air quality data platforms through measuring stations (AQICN 2020).

Figure 4 shows images obtained from the Tropomi instrument, on board the Copernicus Sentinel-5P satellite (ESA 2020), which shows the emissions of nitrogen dioxide $\left(\mathrm{NO}_{2}\right)$ and other pollutants from January 1st until March 11th, 2020.
Fig. 6 Electricity demand in Spain between January and July of 2020 by the Spanish electric network

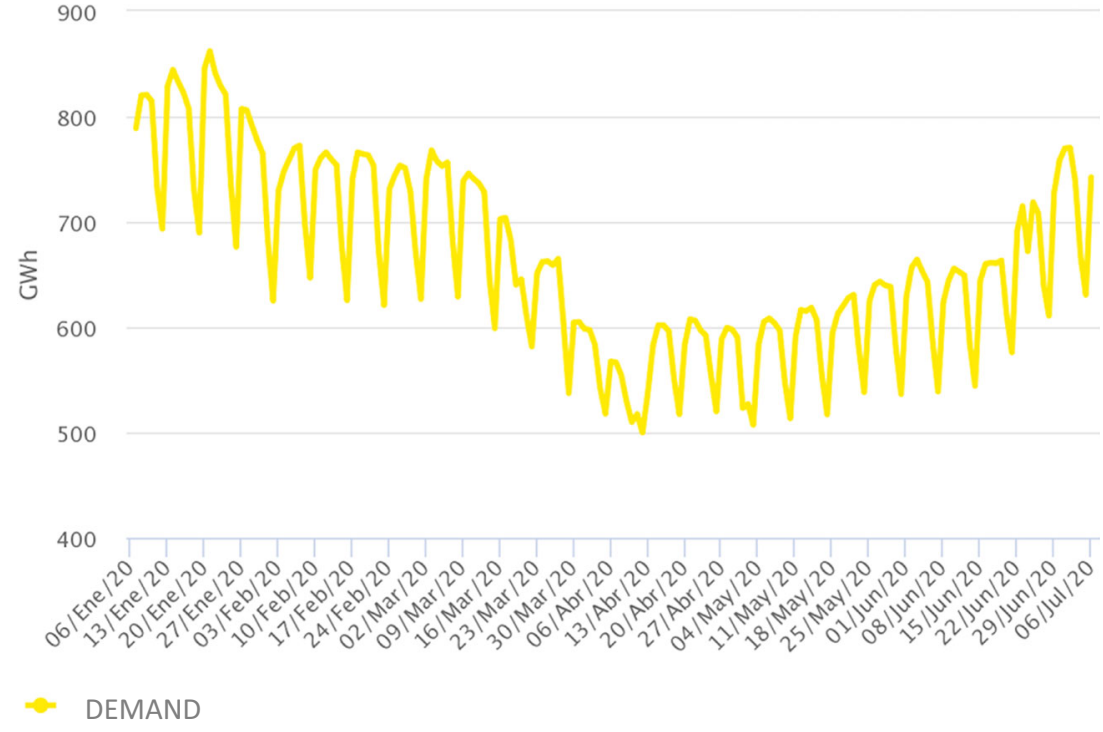


Table 1 Period and phases of deescalation of five Spanish cities

\begin{tabular}{lllllll}
\hline & State alarm & Phase 0 & Phase 1 & Phase 2 & Phase 3 & New normality \\
\hline Valencia & 14 March & 11 May & 18 May & 1 June & 15 June & 21 June \\
Madrid & 14 March & 11 May & 25 May & 10 June & 21 June & 21 June \\
Barcelona & 14 March & 11 May & 25 May & 10 June & 18 June & 19 June \\
Sevilla & 14 March & 4 May & 11 May & 25 May & 10 June & 21 June \\
Bilbao & 14 March & 4 May & 11 May & 25 May & 10 June & 19 June \\
\hline
\end{tabular}

Mainly observed the human-caused pollution, due to emissions from tailpipes and the generation of electricity, especially coal-fired power plants. Nitrogen dioxide emissions have been reduced as a consequence of travel restrictions, and many companies or factories closed, using less energy, along with the measures taken by the government of Italy (first) and Spain (later) to prevent the spread of the disease, which have caused a reduction in traffic and industrial activities.

Nitrogen dioxide emissions $\left(\mathrm{NO}_{2}\right.$, redder in Fig. 4 at higher concentration) have been reduced in northern Italy between mid-January and mid-March 2020; in the same way, this reduction can be seen in Spain (ESA 2020). NOx emission from a large area can be subjected to interannual and other systematic variation. Analyzing NOx emission is particularly tricky due to cloud cover, meteorological influences like wind fluctuation, wind speed, etc. (ACP 2020), but as an approximation, it can take a good reference to see the state of the change in air pollution in the observed places.

The reduction of this pollutant, being one of the most harmful substances expelled by vehicles (especially diesel), is seen especially in northern Italy, coinciding with the national lockdown decreed in order to prevent the spread of COVID-19. Along with this positive effect, it must be highlighted the impact of COVID19 on other fields, such as environmental noise; this factor can present as unwanted issue among citizens living close to locations where industrial activity or traffic activities are presented on high level (Zambrano-Monserrate et al. 2020). Thus, with the mobility restrictions, the environmental noise was reduced noticeably during the lockdown period over areas with high ratio of activities such as industrial, commercial, or related to vehicles (Díaz et al. 2021).

In the case of Spain, the $\mathrm{NO}_{2}$ values can be seen in Fig. 5 of Spain from January 6th to 20th, 2020 (before quarantine) and from March 23rd to April 13th (during quarantine). The data was collected by the Tropospheric Monitoring Instrument (TROPOMI) on the Sentinel-5 satellite of ESA, a related sensor, the Ozone Monitoring Instrument (OMI), and the Aura satellite of NASA, with similar measurements (NASA 2020).

Although Spain's NOX effects and reduction pattern could be very different, observing the change in air pollution produced in other areas due to COVID-19 can serve as a reference for the change that may occur in other countries such as Spain. According to a NASA study, the first evidence of $\mathrm{NO}_{2}$ reduction was seen near Wuhan, but it eventually spread across the country. Millions of people have been lockdown making it one of the biggest actions in human history (WHO 2020a, b).

In Spain, the electricity demand (REE 2020), by observing the three stages of the crisis, first, when there was no public awareness of the COVID-19 impact (A-mid-January 2020), second, after the first alert by the Spanish Government (Bearly March 2020), and third, after the decree of alarm and mobility restriction of the citizens by the government (C-mid-

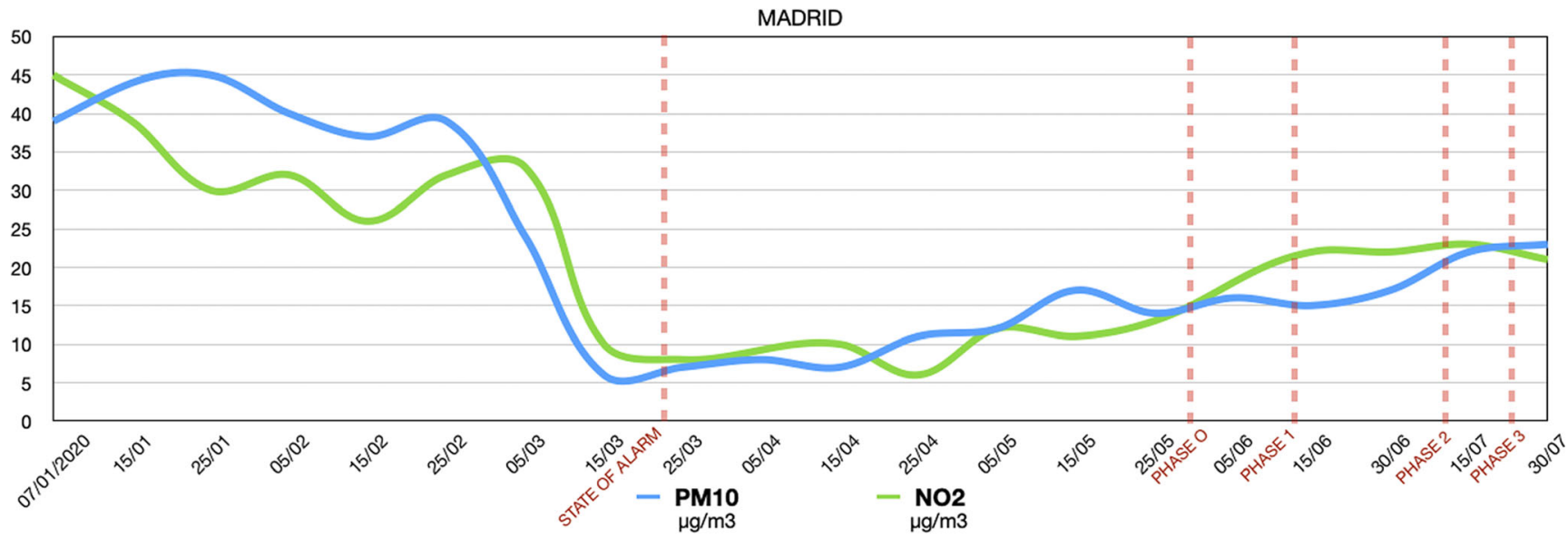

Fig. 7 Chart of air pollutants in Madrid (measuring station of F. Ladreda) in five different stages. First without awareness of the pandemic problem (from January to March). After the decree of alarm and mobility restrictions (14/03/2020). And the different phases of de-escalation from phase 0 to phase 3 


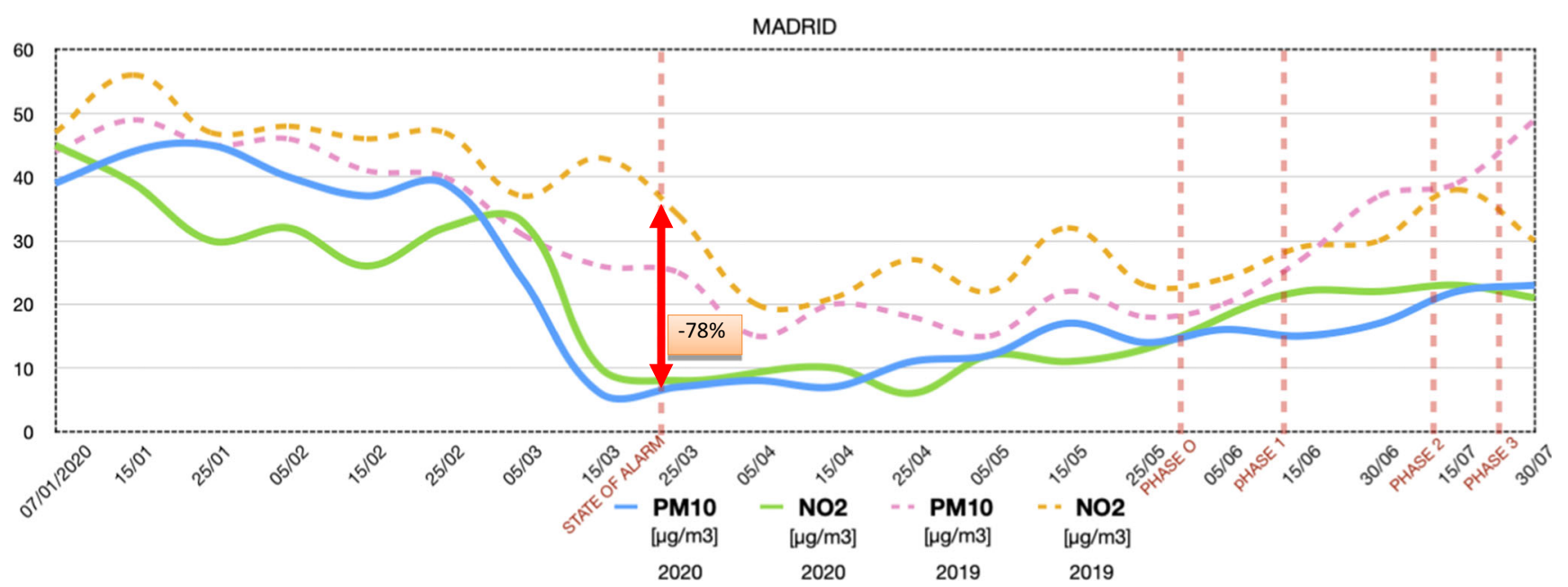

Fig. 8 Data comparison of air pollutants in Madrid (measuring station of F. Ladreda) referring to 2020 and its comparison with 2019

March 2020). Figure 6 then shows the evolution of electricity demand due to the pandemic crisis and actions taken by the Spanish government. Three working days have been taken to show the evolution of electricity consumption (REE 2020): (A) without awareness of the pandemic problem (20/01/ 2020), with a maximum demand of $39,435 \mathrm{MW}$; (B) after first awareness of the crisis (13/03/2020), with a maximum demand of 33,006 MW; and (c) after the decree of alarm and mobility restrictions $(20 / 03 / 2020)$, with a maximum demand of 30,191 MW. It is observed a reduction in energy consumption up to $25 \%$, compared to January. The decrease in demand must be considered as a foreseen action in the following weeks, given since the last day analyzed was 5 days after the alarm decree, and it is foreseeable that more economic activity will stop. This implies lower pollutant emissions as a consequence of electric power production plants.

Observing air quality of five Spanish cities (Madrid, Barcelona, Valencia, Sevilla, and Bilbao) through air pollution monitoring stations, it is shown the significant decrease in pollutants, especially $\mathrm{NO}_{2}$, consequence of the drastic traffic reduction due to mobility restriction ordered by the Spanish government as of March 14th, 2020. The state of alarm and different phases of Spanish countries are shown in Table 1:

From Figs. 7, 8, 9, 10,11, 12, 13, 14, 15, 16, to 17, it is shown how different cities have been affected by the impact of COVID-19. Starting with Madrid (Figs. 7 and 8), elaborated with data collected from the F. Ladreda measuring station:

\section{Analysis of air quality in Madrid}

Madrid is among others, the Spanish city with high levels of pollution, due to a large number of traffic movements every day. Figure 7 shows how the city started the year 2020 and 2019 with values around 58 and 49 of $\mathrm{PM}_{10}$ and $\mathrm{NO}_{2}$. Figure elaborated through data extracted from the air quality data platform (AQICN 2020). This tendency continued until the state of alarm (14/03/2020) after this period, a drastic fall can be seen as a result of restriction in mobility ordered by the

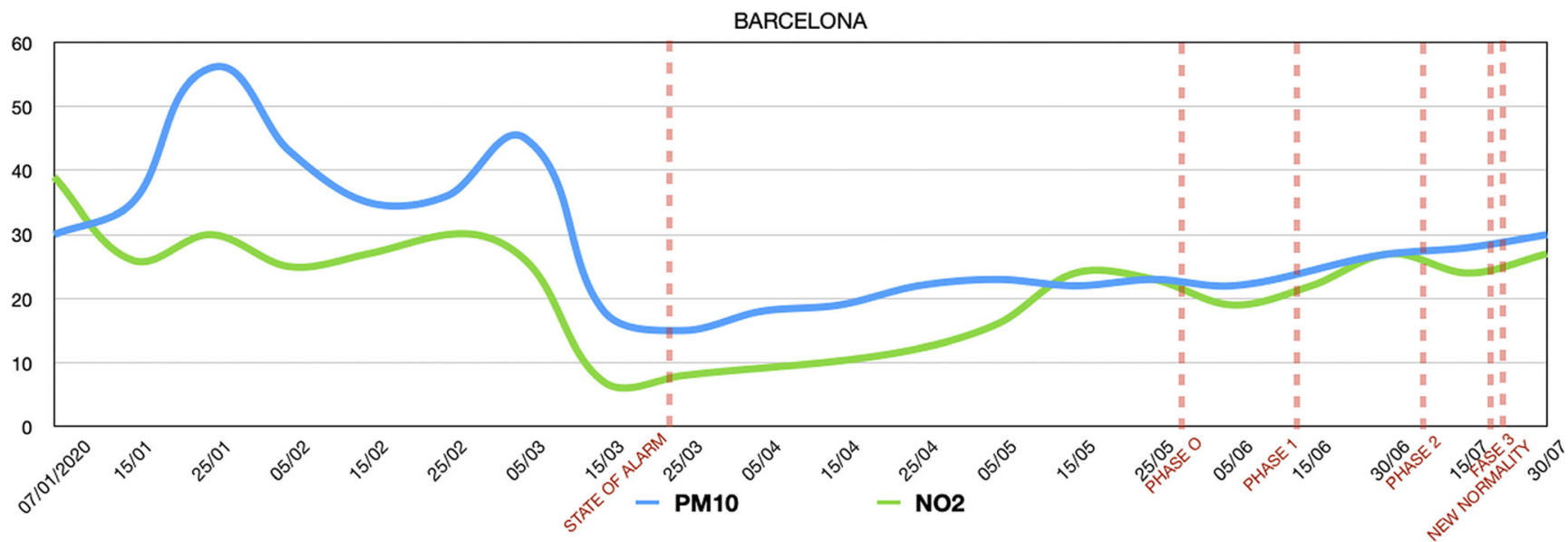

Fig. 9 Graph of $\mathrm{PM}_{10}$ and $\mathrm{NO}_{2}$ in Barcelona (measuring station of L'Eixample) in different stages. First without awareness of the pandemic from January to March. After the decree of alarm and mobility restrictions (14/03/2020). And the different phases of deescalation from phase 0 to new normality 


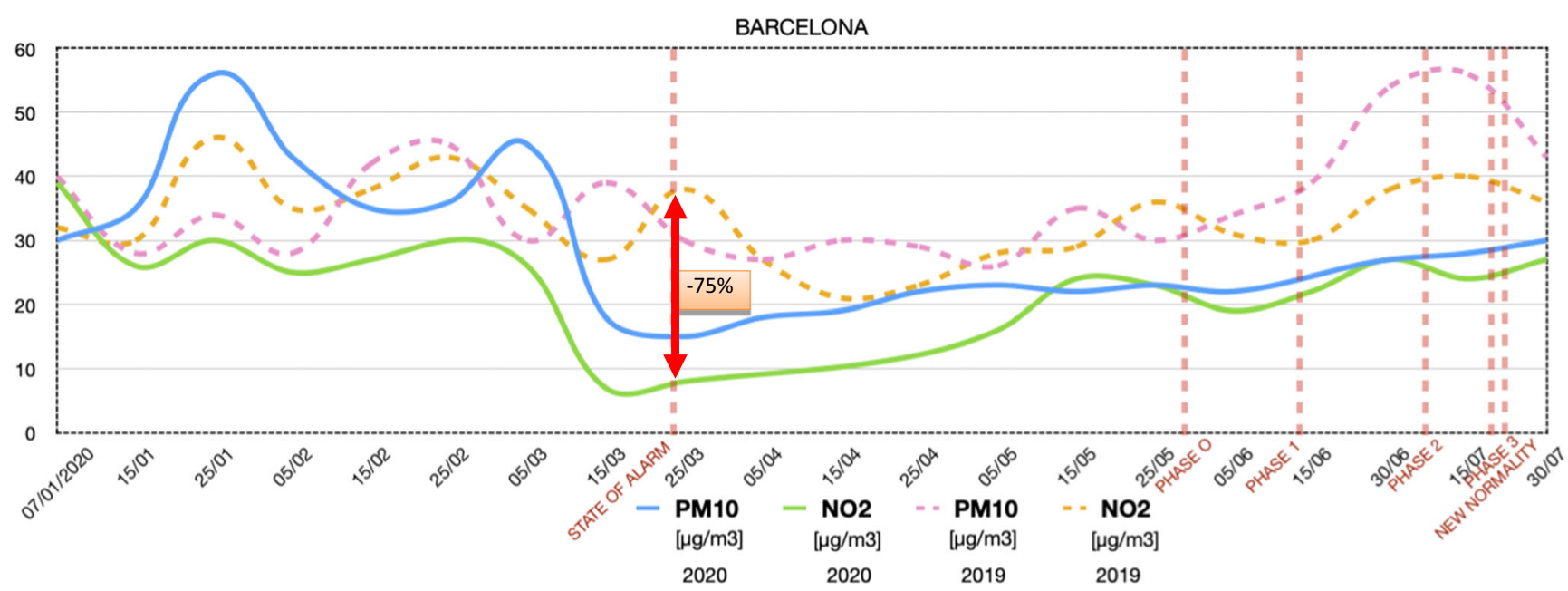

Fig. 10 Data comparison of air pollutants in Barcelona (measuring station of L'Eixample) referring to 2020 and its comparison with 2019

Spanish Government. The low values continue until phase 0, where some uplifting of restrictions took place, resulting in an increase of pollutants as is shown in Fig. 7 (ESA 2020). With each phase, the values increase gradually; however, these values are lower than the values before the pandemic or the year 2019.

\section{Analysis of air quality in Barcelona}

In the case of Barcelona, observing the air quality data through atmospheric pollution monitoring stations in the city center can be observed as a decrease in pollutants, especially $\mathrm{NO} 2$, as a consequence of drastic traffic reduction. $\mathrm{NO}_{2}$ is originated by the combination of nitrogen and oxygen present in the air as a consequence of combustion processes, including road traffic, while $\mathrm{PM}_{10}$ particles are also originated during combustion processes (carbonaceous particles, soot), although they can also have a natural origin (fine sand and other particles) carried by winds.
Barcelona has a high amount of daily traffic which leads to high values of air pollutants in the city, as is shown in Figs. 9 and 10 elaborated with the report collected from the air quality data platform (AQICN 2020), which shows the values reaching up to $58 \mu \mathrm{gr} / \mathrm{m}^{3}$; however, these values are decreased significantly after the state of alarm on 14/03/2020. The recovery of economic activity lifts the values of air pollutants, yet these values remain lower than the period before COVID19 or 2019.

\section{Analysis of air quality in Valencia}

Valencia capital with a total population of 794,288 is another city where traffic is an important source of pollution. The measures of these air pollutants have been done on Pista de Silla, as it is a point of continuous traffic. The values are shown in Figs. 11 and 12 indicate the high amount of $\mathrm{PM}_{10}$ and $\mathrm{NO}_{2}$ reaching values around $50 \mu \mathrm{gr} / \mathrm{m}^{3}$ according to data extracted from the air quality data platform (AQICN 2020).

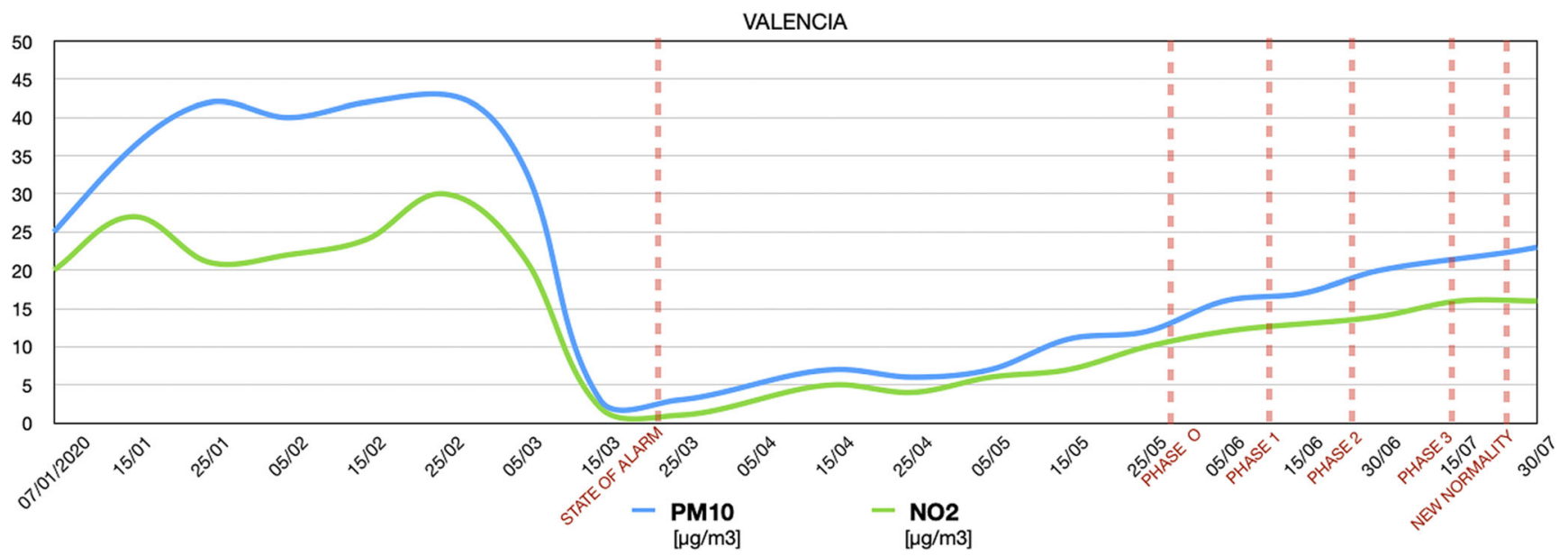

Fig. 11 Chart of air pollutants in Valencia (measuring station of Pista de Silla) in five different stages. First without awareness of the pandemic from January to March. After the decree of alarm and mobility restrictions
(14/03/2020). And the different phases of de-escalation from phase 0 to new normality 


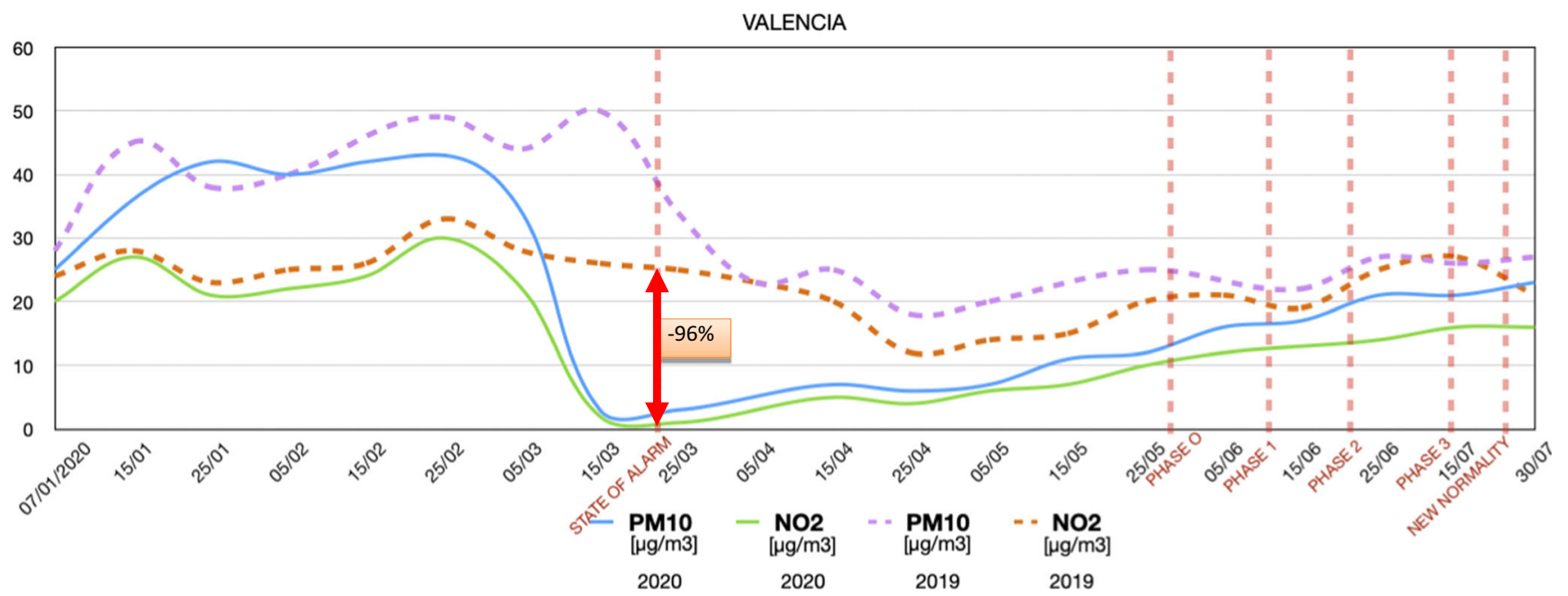

Fig. 12 Data comparison of air pollutants in Valencia (measuring station of Pista de Silla) referring to 2020 and its comparison with 2019

The tendency of these values experienced a substantial fall after the 14th of March of 2020 as the state of alarm was declared which caused a mobility restriction. In Valencia, phase 1 took place on the 11th of May 2020, as it is shown in Fig. 11; the air pollutants start increasing until values reach up to $20 \mu \mathrm{gr} / \mathrm{m}^{3}$. From phase 1 to new normality, the values have been lower than the starting of 2020 or 2019 , due to reduced mobility and less industrial activities.

The variation of pollution regarding the current year (2020) and last year (2019) can be seen in Fig. 13 that analyze the $\mathrm{PM}_{10}$ from mid-January to mid-July.

\section{Analysis of air quality in Seville}

In the case of Seville, the drop in values is shown in Fig. 14, where the airborne pollutants have values of
$35 \mu \mathrm{gr} / \mathrm{m}^{3}$ before pandemic and values up to $50 \mu \mathrm{gr} / \mathrm{m}^{3}$ in 2019. The figure is elaborated with information extracted from the air quality data platform (AQICN 2020). This indicates how the city faces a serious problem of pollution which has increased in recent years with the massive use of road traffic. The air quality in the city reached critical values in the past years which can be solved by the rethinking of the municipal traffic and infrastructure policies. The values from Fig. 15 show the tendency of pollutants from January 2020 until July 2020. After the lockdown, the values remained on lower point, and with the lifting of lockdown (in Spain executed with various phases), these values increased gradually however, remaining on lower numbers than last year (2019) in the same period of time. The lockdown lifting plan is described in Table 2:
Fig. 13 Analysis of $\mathrm{PM}_{10}$ in Valencia on Pista de Silla from January 2020 to July 2020 compared with 2019
2019 PM10

PM10

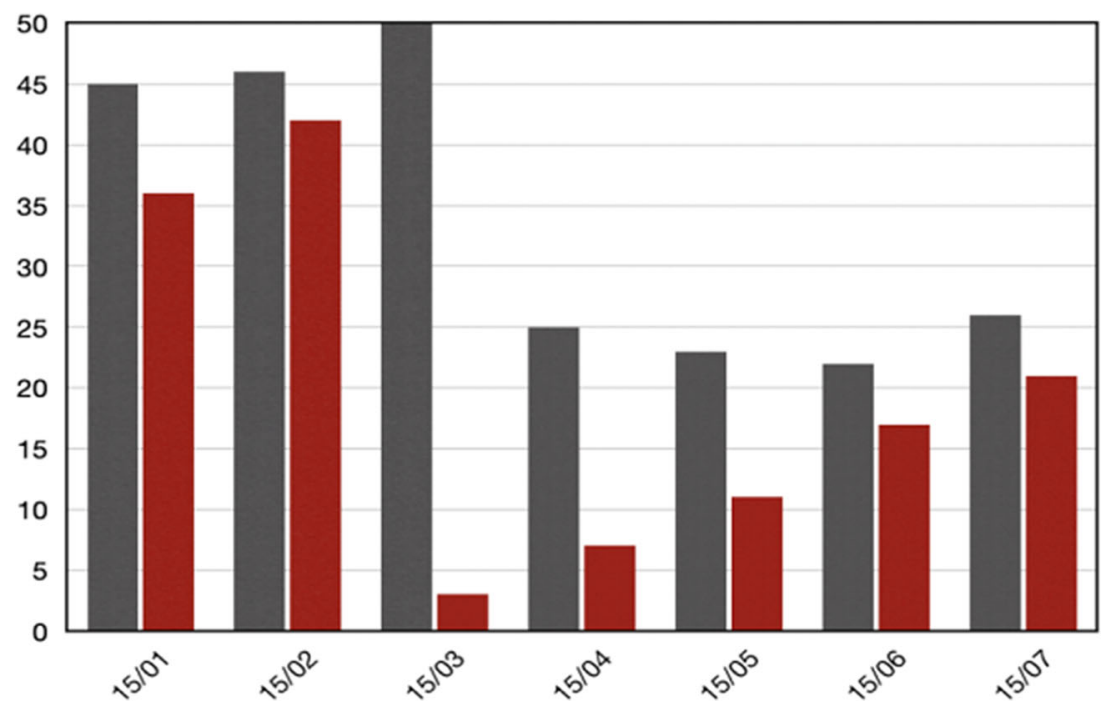


Table 2 Period and phases of deescalation in Sevilla. Source: own elaboration

\begin{tabular}{lllllll}
\hline & State of alarm & Phase 0 & Phase 1 & Phase 2 & Phase 3 & New normality \\
\hline Valencia & 14 March & 11 May & 18 May & 1 June & 15 June & 21 June \\
Madrid & 14 March & 11 May & 25 May & 10 June & 21 June & 21 June \\
Barcelona & 14 March & 11 May & 25 May & 10 June & 18 June & 19 June \\
Sevilla & 14 March & 4 May & 11 May & 25 May & 10 June & 21 June \\
Bilbao & 14 March & 4 May & 11 May & 25 May & 10 June & 19 June \\
\hline
\end{tabular}

\section{Analysis of air quality in Bilbao}

In spite of being a small city compared with other cities mentioned in this article, Bilbao has high levels of pollution due to a large amount of traffic and connections that take place in this city. In terms of airborne pollutants, the tendency is the same as in other large cities; this tendency is shown in Figs. 16 and 17. In the first figure, it shows how the current year started with values reaching up to $45 \mu \mathrm{gr} / \mathrm{m}^{3}$, while on the 14 th of March, there is a drastic fall of these values which creates an important point. With the mobility reduction and less industrial activities, the city shows a better air quality with values of $\mathrm{PM}_{10}$ and $\mathrm{NO}_{2}$ around 7 and $5 \mu \mathrm{gr} / \mathrm{m}^{3}$; data extracted from the air quality data platform (AQICN 2020).

\section{Discussion}

In order to reduce COVID-19 expansion, measures such as traffic restriction, flight cancelations, or factory closures are applied. This has had a positive impact on the environment with less carbon dioxide released into the atmosphere and other pollutants. The same measures applied in China in February allowed emissions to decrease by $25 \%$. In this period, China emitted 150 million metric ton of $\mathrm{CO}_{2}$, less than the quantity recorded a year ago; in 2019, also a reduction in nitrogen dioxide $\left(\mathrm{NO}_{2}\right)$ concentrations have decreased. Italy being the second country with the highest number of confirmed cases of COVID-19 in the world experimented with the same measures with positive results in terms of the environment. The images from the European Space Agency satellite, captured from January 1st until March 11th, 2020, show the diminution of $\mathrm{NO}_{2}$ in China after the lockdown measures began to apply. Similarly, this situation also occurred in cities such as Italy and Spain where mobility and company operations were restricted.

There is a significant fall in atmospheric pollution observed by satellite images (ESA 2020) in Spain, which minimizes the pollutant concentration in large cities of the country. As a consequence of activity decrease, there is a clear reduction in $\mathrm{NO}_{2}$ and $\mathrm{PM}_{10}$ along with lower electricity consumption, which leads to emission reduction by power plants that use fossil fuel.

The city of Valencia (Spain) has observed an immediate reduction of pollutants. Valencia has seven measuring stations, located on "Avenida de Francia, Bulevar Sur, plaza Ayuntamiento, el Molí del Sol (Campanar), Pista de Silla, Universitat Politècnica and Viveros." These stations measure the main pollutant sources present in urban environments such as sulfur $\left(\mathrm{SO}_{2}\right)$ and nitrogen oxides $\left(\mathrm{NO}, \mathrm{NO}_{2}, \mathrm{NOx}\right)$, carbon monoxide $(\mathrm{CO})$, ozone $\left(\mathrm{O}_{3}\right)$, and the suspended particles with fractions less than $10 \mu \mathrm{m}\left(\mathrm{PM}_{10}\right)$ and less than $2.5 \mu \mathrm{m}$

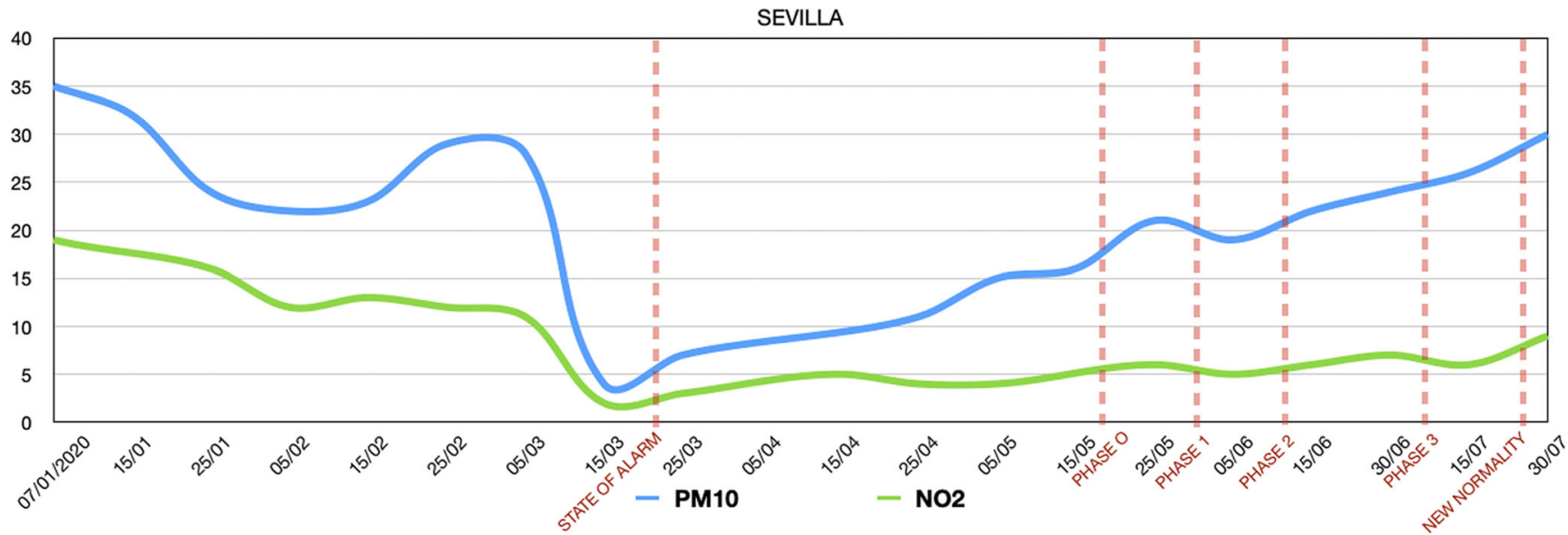

Fig. 14 Graph of $\mathrm{PM}_{10}$ and $\mathrm{NO}_{2}$ in Sevilla (measuring station of Santa Clara) in five different stages. First without awareness of the pandemic from January to March. After the decree of alarm and mobility restrictions

(14/03/2020). And the different phases of de-escalation from phase 0 to new normality 


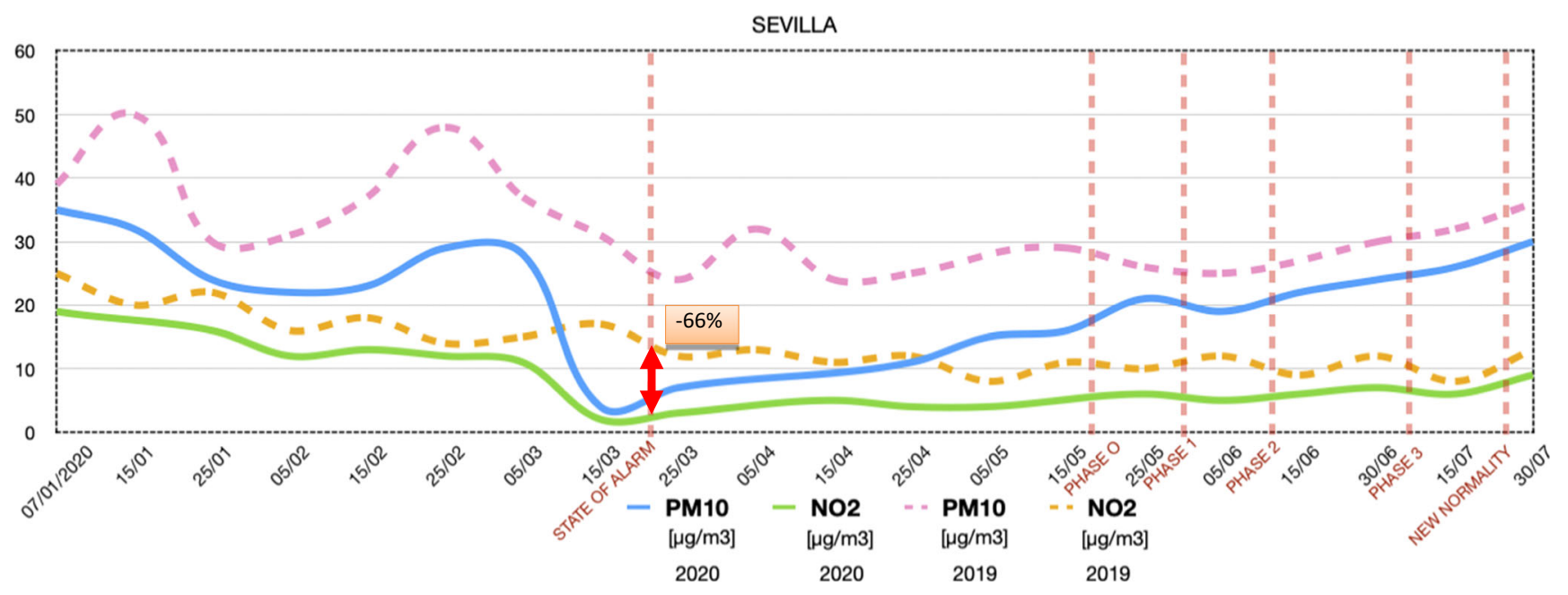

Fig. 15 Data comparison of air pollutants in Sevilla (measuring station of Santa Clara) referring to 2020 its comparison with 2019

$\left(\mathrm{PM}_{2,5}\right)$, and organic compounds (VOCs, benzene, toluene, xylene). Paying particular attention to nitrogen oxide $\left(\mathrm{NO}_{2}\right)$ and $\mathrm{PM}_{10}$ measured during holidays, $\mathrm{NO}_{2}$ pollution levels are reduced by up to $90 \%$ in Pista de Silla on 22/03/2020 (holiday after mobility restriction order) where by measuring it was shown $1 \mu \mathrm{gr} / \mathrm{m}^{3}$ in reference to another holiday prior to the mobility restriction on $(8 / 03 / 2020)$ where by measuring it was shown $12 \mu \mathrm{gr} / \mathrm{m}^{3}$. This difference is even more significant if it compared to holiday dates in January 2020 where $16 \mu \mathrm{gr} / \mathrm{m}^{3}$ $(18 / 01 / 2020)$, when there was still no special awareness on the pandemic problem by the citizens.

Analyzing the $\mathrm{NO}_{2}$ concentrations on working days in Valencia, it can be the observed measurement of de $3 \mu \mathrm{gr} /$ $\mathrm{m}^{3}$ on 20/03/2020 (working day after the decree of mobility restriction), having an average reduction of $79 \%$ compared to next week (12/03/2020) where values of $19 \mu \mathrm{gr} / \mathrm{m}^{3}$ were measured or an average reduction of $85 \%$ in the month of January $(24 / 01 / 2020) 21 \mu \mathrm{gr} / \mathrm{m}^{3}$, when there was still no special awareness on the pandemic crisis by the citizens.
In 1 week, $\mathrm{PM}_{10}$ suspended particles have been reduced by up to $55 \%$ compared to holidays and up to $70 \%$ compared to working days. This reduction is more significant if compared with the same days of January 2020 or compared to 2019 measurements.

The annotations on the city of Valencia can also be discussed regarding the city of Barcelona, where you can see some decreases on holidays of $\mathrm{NO}_{2}$ and $\mathrm{PM}_{10} \cdot \mathrm{NO}_{2}$ pollution levels on holidays are reduced from $22 \mu \mathrm{gr} / \mathrm{m}^{3}(18 / 01 / 2020)$ to $4 \mu \mathrm{gr} / \mathrm{m}^{3}$ (22/03/2020). Comparing $\mathrm{NO}_{2}$ on workdays, it goes from $31 \mu \mathrm{gr} / \mathrm{m}^{3}(12 / 03 / 2020)$ to $9 \mu \mathrm{gr} / \mathrm{m}^{3}$ (20/03/2020). $\mathrm{PM}_{10}$ levels on holidays are reduced in Barcelona from $28 \mu \mathrm{gr} / \mathrm{m}^{3}(18 / 01 / 2020)$ to $15 \mu \mathrm{gr} / \mathrm{m}^{3}(22 / 03 / 2020)$. Comparing $\mathrm{PM}_{10}$ on workdays is passed from $50 \mu \mathrm{gr} / \mathrm{m}^{3}$ (24/01/2020) to $17 \mu \mathrm{gr} / \mathrm{m}^{3}(20 / 03 / 2020)$.

Graphically, it can be seen in Fig. 18, elaborated with information extracted from air quality data platform (AQICN), the significant reduction of $\mathrm{PM}_{10}$ concentrations in the five Spanish cities analyzed (Madrid, Barcelona, Valencia,

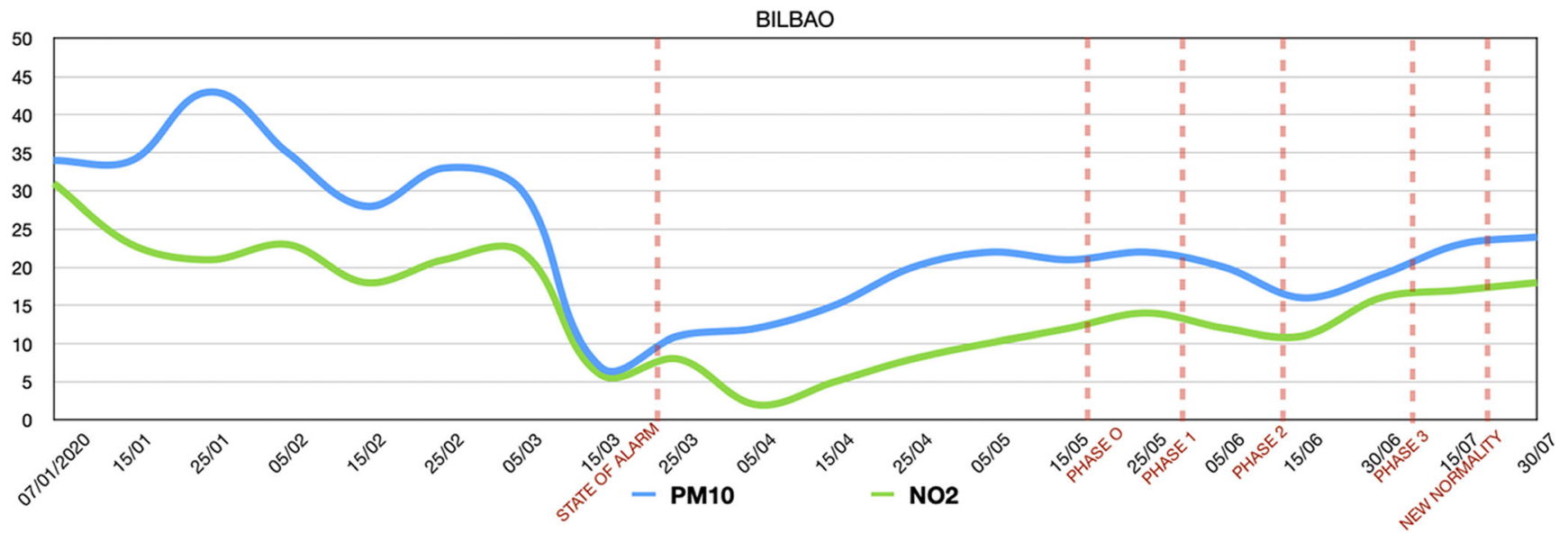

Fig. 16 Graph of $\mathrm{PM}_{10}$ and $\mathrm{NO}_{2}$ in Bilbao (measuring station of $\mathrm{M}^{\mathrm{a}}$ Díaz Haro) in five different stages. First without awareness of the pandemic from January to March. After the decree of alarm and mobility restrictions
(14/03/2020). And the different phases of de-escalation from phase 0 to new normality 


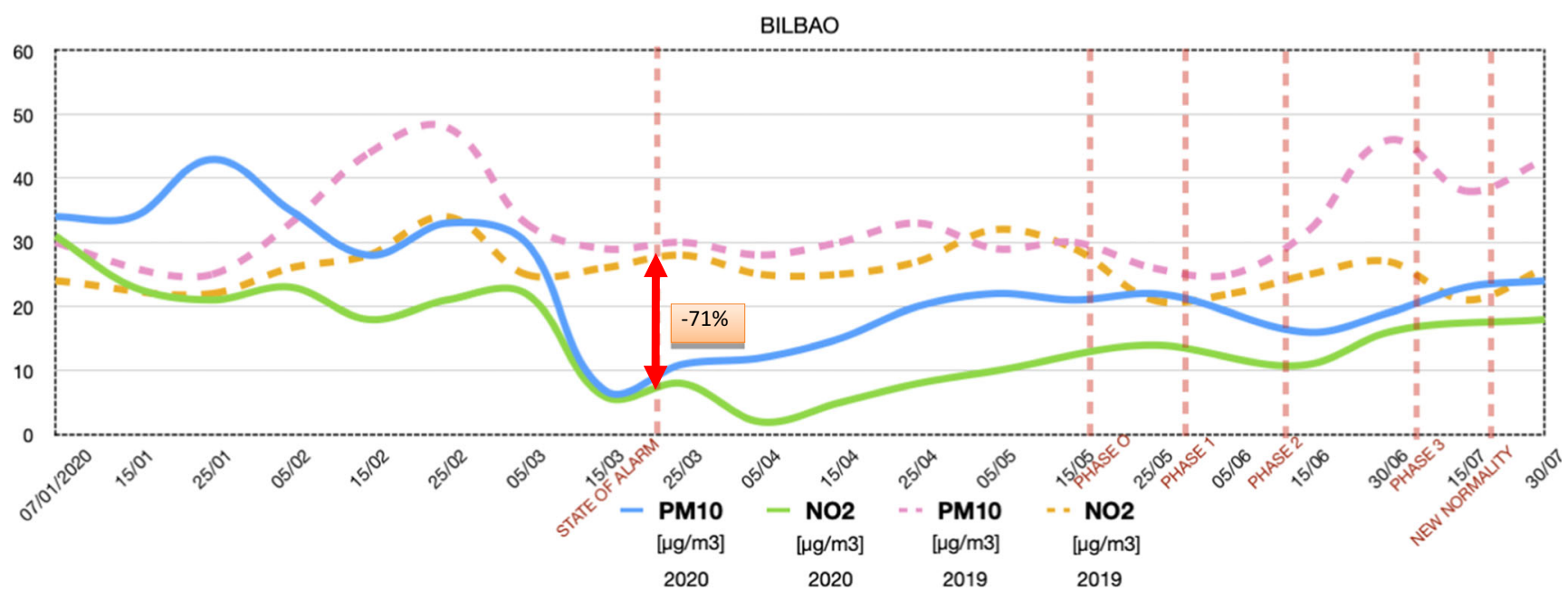

Fig. 17 Data comparison of air pollutants in Bilbao (measuring station of $\mathrm{M}^{\mathrm{a}}$ Díaz Haro) referring to 2019 its comparison with 2020

Bilbao, and Sevilla), comparing 1 month prior to the lockdown and after lockdown.

A mobility restriction has caused a decrease in private traffic, being this one of the main factors of urban air pollution; all this shows a significant drop in suspended pollutant particles.

There has been a significant reduction in polluting particles according to the recorded data. This reduction occurred on March 15th, the first day of effective quarantine (domiciliary confinement was ordered), in comparison to the previous week without any substantial change in the dispersion meteorological conditions between both dates.

In the case of Spain specific days (before and after lockdown) have been analyzed for data comparison. It is always observed a significant reduction in air pollution. This result reinforces the significant impact of human activity on the environmental quality of cities (Gómez et al. 2018; Condereff project, 2020; Grow Green project 2020) and highlights the importance of seeking formulas to make the environment where we live more sustainable (Peñalvo-López et al. 2020; Cárcel-Carrasco et al. 2020; Peñalvo-López et al. 2017, 2019), combining mobility freedom with environmental respect.

\section{Conclusions}

Based on the analysis and data collection of air pollutants $\left(\mathrm{PM}_{10}\right.$ and $\left.\mathrm{NO}_{2}\right)$ from different regions of Spanish territory, it has been prepared a comparative study in order to display the influence of traffic and human mobility on air quality. This study was conducted during and after the lockdown period. This same period of time has been compared to the year 2019 when there was no confinement. The pattern of pollution was
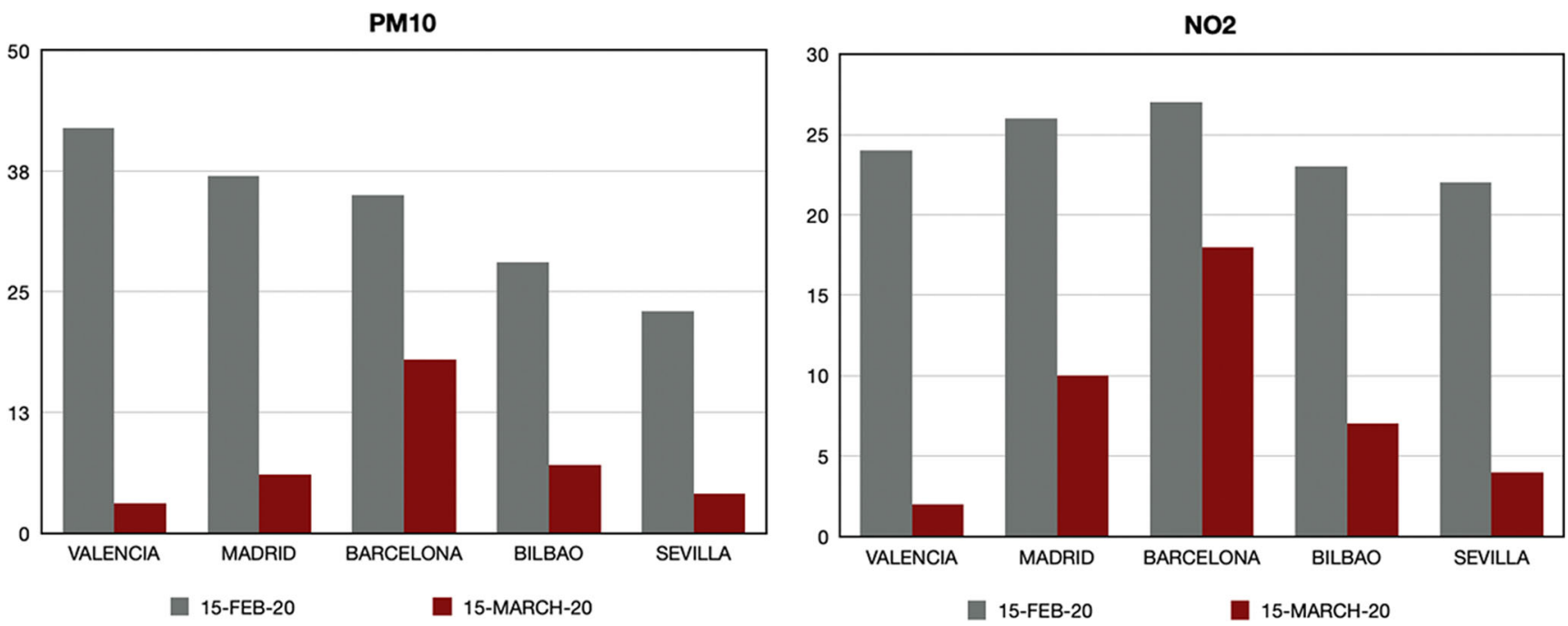

Fig. $18 \mathrm{PM}_{10}$ and $\mathrm{NO}_{2}$ concentrations $\left(\mu \mathrm{gr} / \mathrm{m}^{3}\right.$ ) on working days in Valencia, Madrid, Barcelona, Bilbao, and Sevilla. In gray, before the decree of alarm and mobility restrictions (15/02/2020). In red, after the decree of alarm and mobility restrictions (15/03/2020). Source: own elaboration 
altered during the lockdown period such as a decrease in air pollutants was shown over different cities (Venter et al. 2020).

The COVID-19 pandemic clearly shows the interconnection between human and planetary health (Web3 2020). Despite being in the technological era, humankind struggled against the health disaster which abruptly appeared. To control this pandemic, most countries adopted, as an effective measure, the lockdown on social and economical activities in order to avoid the transmission of the virus. All this shows a significant drop in suspended pollutant particles. First, a drastic decrease in pollution in China was observed, later on in Italy and almost immediately in Spain. Due to the pandemic crisis and actions taken by the Spanish government, the electricity demand has been considerably reduced up to $25 \%$ compared to January, referring to the week after applying the alarm state (14/03/2020). This implies lower pollutant emissions as a consequence of electric power production plants.

Regarding the air pollutants and its analyzed data in this article indicate the downturn of pollutants such as $\mathrm{PM}_{10}$ and $\mathrm{NO}_{2}$, reaching the average values of reduction of 70 to $80 \%$ taking into account dates after the decree of alarm and mobility restriction by the Spanish government (14/03/2020), compared to days prior to that date. The decline of these pollutants shows a similar tendency in all Spanish cities where the period after the lockdown was identified by the reduction values of $\mathrm{PM}_{10}$ in Valencia of $88.89 \%$ and in Madrid of $87.5 \%$; in Barcelona, the reduction in $\mathrm{PM}_{10}$ was $70 \%$, in Sevilla $86.8 \%$, and in Bilbao of $87.8 \%$. The same tendency was shown for $\mathrm{NO}_{2}$.

It must be considered the rising of pollution levels once the economy is reactivated. However, this situation can be controlled by taking necessary measures to reduce greenhouse gas emissions and environmental pollution in large cities. It is remarkable the long-term impact from the emergence of COVID-19 which demands the reshaping of environmental policies in order to improve the air quality mainly in urban areas.

Acknowledgements The authors are grateful for the support of the Institute of Materials Technology of the Polytechnic University of Valencia (Spain).

Author contribution Javier Cárcel developed the methodology; Javier Cárcel, Manuel Pascual, and Jaime Langa prepared the conceptualization and data curation; Javier Cárcel and Jaime Langa gathered and analyzed the data. Javier Cárcel and Manuel Pascual review and editing; funding acquisition, Javier Cárcel; Javier Cárcel wrote the paper. All authors read and approved the final manuscript.

Funding This work was supported by the European Union under the project Green Cities for Climate and Water Resilience, Sustainable Economic Growth, Healthy Citizens and Environments with reference 730283 and the framework of Condereff project (Ref. PGI05560Condereff) Construction \& demolition waste management policies for improved resource efficiency.
Data availability In references section.

\section{Declarations}

Ethics approval and consent to participate Not applicable.

Consent for publication Not applicable.

Competing interests The authors declare no competing interests.

\section{References}

ACP. Atmosphere Copernicus programme (2020) Available online: https://atmosphere.copernicus.eu/flawed-estimates-effectslockdown-measures-air-quality-derived-satellite-observations?q= flawed-estimates-effects-lockdown-measures-air-quality-satelliteobservations. Accessed on 22/06/2020

AQICN. Air quality historical data platform. Available online: https:// aqicn.org/data-platform/register/. Accessed on 01/08/2020

Cárcel-Carrasco J, Cárcel-Carrasco JA, Peñalvo-López E (2020) Factors in the relationship between maintenance engineering and knowledge management. Appl Sci 10(8):2810. https://doi.org/10.3390/ app10082810

Condereff project. Construction $\&$ demolition waste management policies for improved resource efficiency. Available online: https:// www.interregeurope.eu/condereff/. Accessed on 21/07/2020

Díaz J, Antonio-López-Bueno J, Culqui D, Asensio C, Sánchez-Martínez G, Linares C (2021) Does exposure to noise pollution influence the incidence and severity of COVID-19? Environ Res 110766:110766. https://doi.org/10.1016/j.envres.2021.110766

Dutheil F, Baker JS, Navel V (2020) COVID-19 as a factor influencing air pollution? Environ Pollut (Barking, Essex: 1987) 263:114466. https://doi.org/10.1016/j.envpol.2020.114466

EPA (2020) The United States Environmental Protection Agency: Office of Air and Radiation. The benefits and costs of the Clean Air Act from 1990 to 2020 . Available on: https://www.epa.gov/sites/ production/files/2015-07/documents/fullreport_rev_a.pdf (2011) (Accessed on 19th March 2020)

ESA/Copernicus. Available online: URL: https://www.esa.int/esearch? $\mathrm{q}=$ covid-19. Accessed on 20/03/2020

Farrow A, Miller KA, Myllyvirta L (2020) Toxic air: the price of fossil fuels. Seoul: Greenpeace Southeast Asia. 44 pp. https://es. greenpeace.org/es/wp-content/uploads/sites/3/2020/02/TOXICAIR-Report-110220.pdf. Accessed on 16/03/2020

Gómez F, Valcuende M, Matzarakis A, Cárcel-Carrasco J (2018) Design of natural elements in open spaces of cities with a Mediterranean climate, conditions for comfort and urban ecology. Environ Sci Pollut Res 25(26):26643-26652. https://doi.org/10.1007/s11356018-2736-1

Grow Green project. Green cities for climate and water resilience, sustainable economic growth, healthy citizens and environments. Available online: http://growgreenproject.eu/. Accessed on 21/07/2020

IEA -International Energy Agency. Available online: https://www.iea. org/. Accessed on 22/07/2020

NASA. National Aeronautics and Space Administration. Available online: URL: https://maps.s5p-pal.com. Accessed on 17/09/2020

Peñalvo-López E, Cárcel-Carrasco J, Devece C, Morcillo AI (2017) A methodology for analyzing sustainability in energy scenarios. Sustainability. 9(9):1590. https://doi.org/10.3390/su9091590

Peñalvo-López, E.; Pérez-Navarro, Á.; Hurtado, E.; \& Cárcel-Carrasco, F. J (2019). Comprehensive methodology for sustainable power 
supply in emerging countries. Sustainability. 11.19: 5398. doi: https://doi.org/10.3390/su11195398

Peñalvo-López E, Cárcel-Carrasco J, Alfonso-Solar D, Valencia-Salazar I, Hurtado-Pérez E (2020) Study of the improvement on energy efficiency for a building in the Mediterranean area by the installation of a green roof system. Energies. 13(5):1246. https://doi.org/10. 3390/en13051246

REE. Red Eléctrica de España. Available online https://www.ree.es/es/ actividades/demanda-y-produccion-en-tiempo-real. Accessed on $22 / 05 / 2020$

Rodríguez-Urrego D, Rodríguez-Urrego L (2020) Air quality during the COVID-19: PM2. 5 analysis in the 50 most polluted capital cities in the world. Environ Pollut:115042. https://doi.org/10.1016/j.envpol. 2020.115042

Rojas NY, Ramírez O, Belalcázar LC, Méndez-Espinosa JF, Vargas JM, Pachón JE (2021) PM2. 5 emissions, concentrations and air quality index during the COVID-19 lockdown. Environ Pollut (Barking, Essex: 1987) 272:115973. https://doi.org/10.1016/j.envpol.2020. 115973

SEPAR. Sociedad Española de Neumología y Cirugía Torácica. Available online: https://www.separ.es/. Accessed on 06/07/2020

Venter ZS, Aunan K, Chowdhury S, Lelieveld J (2020) COVID-19 lockdowns cause global air pollution declines. Proc Natl Acad Sci 117(32):18984-18990. https://doi.org/10.1073/pnas.2006853117
Web1. Novel coronavirus spread tracking. Available online: https:// graphics.reuters.com/CHINA-HEALTH-MAP/0100B59S39E/ index.html. Accessed on 17/09/2020

Web2. El comercio. Available online: URL:https://www.elcomercio. $\mathrm{com} /$ tendencias/aislamiento-covid19-reduccion-contaminacionambiente.html. Accessed on 20/03/2020

Web3. COVID-19 and air pollution: a deadly connection. Available online: https://www.weforum.org/agenda/2020/04/the-deadly-linkbetween-covid-19-and-air-pollution/2020/04/the-deadly-linkbetween-covid-19-and-air-pollution/. Accessed on 17th of September 2020

WHO. World Health Organization. Available online: https://www.who. int/es. Accessed on 22/06/2020a

WHO. World Health Organization. Available online: URL: https:/www. who.int/emergencies/diseases/novel-coronavirus-2019/situationreports/. Accessed on 17/09/2020b

Zambrano-Monserrate MA, Ruano MA, Sanchez-Alcalde L (2020) Indirect effects of COVID-19 on the environment. Sci Total Environ 728:138813. https://doi.org/10.1016/j.scitotenv.2020. 138813

Publisher's note Springer Nature remains neutral with regard to jurisdictional claims in published maps and institutional affiliations. 